\section{Formal Education Can Affect Students' Perception of Organic Produce}

\author{
Gerardo H. Nunez, Alisson P. Kovaleski, and Rebecca L. Darnell ${ }^{1}$
}

AdDitional INDEX wORDs. agricultural literacy, college-aged, consumer, purchase behavior

SuMmARY. Consumer perception plays an important role in the decision to purchase organic vs. conventional produce. A web-based survey was used to evaluate perceptions and purchase behavior toward organic produce in a sample population of college-aged students. The effect of formal education on this perception was also investigated. Most subjects in this sample population were aware of and had positive perceptions of organic produce and organic agriculture. The likelihood of being an organic consumer was similar across genders, ages, and fields of study. Subjects who reported to be organic consumers associated less risk with organic produce than those who reported to never have purchased organic produce. A 50 -minute lecture about organic agriculture altered the perception students had about organic produce. After the lecture, students expressed bleaker perceptions about the health benefits and ethical soundness of organic agriculture. On the other hand, after the lecture students expressed a more positive perception of the policies and regulations that govern the organic foods market. Overall, data suggest that students' perception of organic produce and agriculture is based on anecdotal evidence and that formal education on the topic of organic agriculture can affect this perception.

$\mathrm{T}$ The organic products market has been steadily growing throughout the world (Shi-ming and Sauerborn, 2006). In the United States, sales of organic products reached $\$ 21.1$ billion in 2008 (U.S. Department of Agriculture, 2012), continuing the upward trend observed over the last decade. This rapidly expanding consumer base has changed the organic foods marketplace. Since 2000, more organic food has been purchased in conventional supermarkets than in any other venue in the United States, including specialty stores (Dimitri and Greene, 2002). This suggests that consumers are often presented with competing organic and conventional product choices. Fresh produce comprises the majority of the organic food products sold (Dimitri and Greene, 2002) and is the focus of this study. Given the likelihood that consumers make comparisons between organic and conventional produce, consumer perception plays an important role in making the decision to purchase organic (Lockie et al., 2002; RoitnerSchobesberger et al., 2008; Tung et al., 2012).

There is a growing body of literature describing the motivators for buying organic foods, and more

Horticultural Sciences Department, University of Florida, PO Box 110690, Gainesville, FL 32611

${ }^{1}$ Corresponding author. E-mail: rld@ufl.edu. specifically organic produce. Research has shown that organic purchases are driven mostly by health and price considerations (Gracia and Magistris, 2008; Lockie et al., 2002; Ozguven, 2012). Organic produce is generally perceived as healthier than conventional produce (Anderson et al., 2006; Lea and Worsley, 2005), although there is no scientific consensus supporting this (Bourn and Prescott, 2002; Chen, 2005; Huber et al., 2011; Siderer et al., 2005 ). Additionally, organic produce is perceived as fresher, with higher nutritional quality compared with conventional produce. Further, the "functional food" or nutraceutical properties are often perceived to be greater in organic produce compared with conventional produce (Naspetti and Zanoli, 2009; Shafie and Rennie, 2012). On the other hand, higher prices of organic produce are often a limitation to consumption (Lea and Worsley, 2005; Lockie et al., 2002).

Food safety and environmental impact are additional motivators for buying organic produce (Lockie et al., 2002; Ozguven, 2012; Shafie and Rennie, 2012; Siderer et al., 2005). Presence of pesticide residues and other chemicals on produce are the most common food safety concerns of organic and conventional consumers alike (Tung et al., 2012). Although concerns about the environment are not always the strongest driving force for organic consumption (Lockie et al., 2002; Siderer et al., 2005), commitment to environmental and social justice may become more important as consumption increases (Hjelmar, 2011; Seyfang, 2006).

The level of education is also an important predictor of organic consumption. A higher level of education is a characteristic of organic buyers in Germany (Bravo et al., 2013), Norway (Storstad and Bjørkhaug, 2003), and Thailand (Roitner-Schobesberger et al., 2008; Sangkumchaliang and Huang, 2012) among others (Shafie and Rennie, 2012). In Australia, people who received scientific education consumed more organic produce than those who received general education (Lockie et al., 2002), suggesting that the content of the education received also plays a role in the likelihood to buy organic produce.

Consumer perception of organic produce warrants further research, particularly in understudied demographic groups such as college-aged consumers. Most of the previously cited work examined purchase behavior and perceptions with respect to organic produce in noncollege-aged populations. However, evidence suggests that consumer perception of organic produce and purchase behavior differ among age groups (Bravo et al., 2013; Lockie et al., 2002; Sangkumchaliang and Huang, 2012); thus, previous studies may not accurately describe younger populations. It is essential to study younger consumers as a way to assess future consumer perceptions and anticipate challenges to be faced by the industry. Moreover, college-aged populations are ideal to gauge the effect of formal education because they are predisposed to learn and willing to participate in survey-type experiments. Finally, since higher education levels are a demographic descriptor of organic consumers (Bravo et al., 2013; Roitner-Schobesberger et al., 2008; Sangkumchaliang and Huang, 2012; Storstad and Bjørkhaug, 2003), college students represent the youngest segment of this consumer group. Thus, the hypotheses tested in this study were that students' perception of organic produce l) differs between buyers and nonbuyers of organic produce and 2) can be affected by formal education. A survey was designed to evaluate university students' purchase behavior and perceptions with 
respect to organic produce. The extent to which formal education in this area can influence this perception was also tested.

\section{Materials and methods}

SURVEY INSTRUMENT. A 53-item survey was designed and assigned as an extra credit assignment for a 1-credit, general interest horticulture course at the University of Florida, and administered through the online software surveymonkey.com (SurveyMonkey Inc., Palo Alto, CA). Participation in the study was voluntary and complied with the guidelines of the University of Florida Institutional Review Board. The survey instrument consisted of three sections. The first section contained questions about the demographic characteristics of the participants. The second section contained questions asking participants to classify themselves by purchase behavior in one of three groups: 1) those who have never heard of organic produce, 2) those who have heard of organic produce but never purchased any, and 3 ) those who have heard of and bought organic produce. Questions used in this section were designed for a study with similar objectives to this one (Sangkumchaliang and Huang, 2012). The validity and reliability of this section was assumed to be the same as that of the original source. The third section of the survey contained a subset of questions taken from a questionnaire designed by Anderson et al. (2005), who surveyed the perceptions of college-aged consumers about organic and genetically modified produce. Only questions about organic produce were selected for this study. These questions were designed around the various constructs identified by Anderson et al. (2005) to be motivators of the purchase of organic produce; namely: health, environment, risk, ethics, and policy/ regulation. Students were presented with statements and then asked to indicate their level of agreement using a seven-point Likert scale where 1 was "strongly disagree" and 7 was "strongly agree." Both positively and negatively worded statements were presented in every construct. In total, there were 12 statements about health, 8 about environment, 10 about risk, 8 about ethics, and 7 about policy/ regulation. For this section of the survey, reliability was assessed through a pilot study in the intended sample population. Students were asked to respond to the questions in Anderson et al. (2005) via an online platform. Data from this pilot study were regressed on the data collected later from the entire sample population. Results were found to be consistent $(r \geq 0.93)$, suggesting this section of the survey was reliable. The face validity of this section was assumed to be the same as that determined by an expert panel used by Anderson et al. (2005).

While Anderson et al. (2005) assessed student perception of organic produce, the objectives of this study were to assess initial student perception and then determine whether subsequent education altered those perceptions. Additionally, this study sought to relate student perception (Section 3) and purchase behavior (Section 2) in this sample population.

Students from the class were randomly assigned to one of two groups of 163 students each. The first group took the survey the week before a 50-min lecture about organic agriculture, while the second group took the survey the week following the lecture. There was an $88.3 \%$ response rate for the first group and a $95.1 \%$ response rate for the second group. Analyses combined both groups into a 299 respondent data set, unless otherwise stated. The lecture on organic agriculture was given by a $\mathrm{PhD}$ level state extension specialist whose work focuses on organic horticultural production, and included peer-reviewed information relevant to the five constructs (Table 1).

GENERAL PERCEPTION WITHIN A construct. To assess the typical students' perception of organic produce (regardless of age, gender, propensity to buy organic, or education), only the responses from the prelecture survey group $(n=144)$ were used since they represent the perception before any formal education effect. Positively and negatively worded statements were used. Students' responses to negatively worded statements were reverse coded, so that a response of 1 scored 7 points and a response of 7 scored 1 point. Cronbach's alpha coefficient was computed for all constructs using SAS (version 9.3; SAS Institute, Cary, NC). Each student's responses were averaged within each construct. A test was used to determine if the set of average responses in each construct was significantly different from neutral (Ho: mean $=4, P \leq 0.05$ ).

Effects of Age, gender, AWARENESS, FIELD OF STUDY, AND EDUCATION. Responses to Sections 1 and 2 of the survey were used to group students by age, gender, field of study, and likelihood of being an organic consumer. To assess the effect of education on responses, the sevenpoint Likert scale (Section 3) was divided into three categories: "In agreement" (responses 5, 6, and 7), "Neutral" (response 4), and "In disagreement" (responses 1, 2, and 3). Chi-square tests were used to test differences in the ratio of responses among the student groups. For example, responses from the pre-lecture group were used as the expected ratios and responses from the post-lecture group were used as the observed ratios for the chi-square test.

\section{Results and discussion}

Demographics. Of the 299 respondents, $61.5 \%$ were females and $38.5 \%$ were males (data not shown). The majority of respondents were 23 years old or younger $(97.3 \%)$, with the most represented age group between 18 and 20 years old (57.5\%). Students younger than 18 years old were not admitted to this study. Participants were asked to indicate the college they belonged to as a way to assess their level of exposure to agriculture, and science, at large. Students enrolled in colleges that offer both science and nonscience majors were asked to indicate which of these groups (i.e., "science" or "nonscience") best described their field of study. All colleges that offer undergraduate degrees at the University of Florida were represented in this sample population. Students from the College of Agricultural and Life Sciences represented $29.0 \%$ of the respondents. Other colleges with high representation were the College of Liberal Arts and Sciences (22.8\%) and the Warrington College of Business Administration (16.8\%).

AWARENESS AND CONSUMPTION. Most respondents displayed some level of awareness about organic produce $(98.3 \%)$. Only three respondents reported to be unaware of organic produce, therefore, "unaware of organic" was not used as a category for 
data analysis. The majority of respondents $(77.3 \%)$ reported they were buyers of organic produce, compared with $12.7 \%$ who indicated they were nonbuyers, and $10.0 \%$ who indicated they were unsure if they had bought

Table 1. Topics covered by an external subject area expert in a 50-min lecture about organic agriculture delivered to a sample population of undergraduate students at the University of Florida.

1) Brief history of organic agriculture

2) The organic marketplace

a. Trends in consumption of organic products

b. Important producers, retailers, and consumers globally and domestically

3 ) The meaning behind "organic"

a. The process of USDA certification

b. Design and planning of space and

c. Nutrient management

USDA National List of Allowable and Prohibited Substances

Role of the Organic Materials Review Institute

d. Seed and biological stock management

Exclusion of genetically modified organisms

e. Soil management

Reducing soil erosion and maintaining/improving soil quality

f. Pest management

Biological and cultural controls

4) Accuracy vs. advocacy

a. Critical thinking strategies

b. Resources for future learning logistics in farms

organic produce (Table 2). There were no differences among age groups, with $75.0 \%$ to $79.0 \%$ of respondents reporting having purchased organic produce. Similarly, there were no significant differences between male and female respondents, with $72.3 \%$ to $78.3 \%$ of respondents, regardless of gender, indicating they have purchased organic produce (Table 2). These results contrast with reports from other populations in the United States and abroad showing females are more likely to purchase organic than males (Byrne et al., 1991; Sangkumchaliang and Huang, 2012). However, these previous studies compared the proportion of female and male buyers among organic consumers, while this study compared the proportion of organic buyers vs. nonbuyers within each gender. The latter is a measure of gender differences, while the former merely describes the consumer base and can be affected by the gender composition of a sample population. Females comprise the majority of organic buyers in the current sample population (data not shown) but there are similar proportions of male and female organic buyers, suggesting there is no gender bias in purchase behavior.

Field of study did not affect the likelihood of being an organic consumer in this sample population. There were no differences between the responses of students majoring in agriculture-related fields and the responses of those majoring in other fields (data not shown). Responses of students majoring in science fields were

Table 2. Responses to questions about organic produce purchasing behavior as a function of age, gender, and field of study in a sample population of undergraduate students surveyed at the University of Florida.

\begin{tabular}{lccc}
\hline Demographic (no. respondents) & ${\text { Buyer }(\%)^{\mathrm{z}}}^{\mathrm{N}}$ & Nonbuyer $(\%)^{\mathrm{y}}$ & ${\text { Not sure }(\%)^{\mathrm{x}}}^{\mathrm{w}}$ \\
\hline Total (299)w & 77.26 & 12.71 & 10.03 \\
Age group & & & \\
$\quad$ 18-20 years (172) & 76.16 & 11.63 & 12.21 \\
21-23 years (119) & 78.99 & 14.29 & 6.72 \\
$\quad>23$ years (8) & 75.00 & 12.50 & 12.50 \\
Gender & & & \\
$\quad$ Female (184) & 72.28 & 10.87 & 11.41 \\
$\quad$ Male (115) & 78.26 & 14.78 & 6.96 \\
Field of study & & & \\
$\quad$ Science (101) & 76.24 & 11.88 & 11.88 \\
$\quad$ Nonscience (197) & 78.17 & 13.20 & 8.63 \\
\hline
\end{tabular}

${ }^{2}$ Respondents who had heard of and purchased organic produce.

${ }^{y}$ Respondents who had heard of, but not purchased, organic produce.

${ }^{x}$ Respondents who were not sure if they had purchased organic produce.

wome questions were left unanswered, hence the number of respondents does not always add up to 299 grouped and compared with those of students majoring in other fields. No significant difference was found between these groups (Table 2). These results differ from previous work, where self-reported scientific education was characteristic of greater consumption of organic produce (Lockie et al., 2002). The sample population described in this study was more homogenous with respect to level of education and age than the sample population surveyed by Lockie et al. (2002). Therefore, scientific education may indeed have an effect on the likelihood of organic purchase, depending on the extent of formal education and the age of the sample population. Scientific education differences may not have shown up in the present survey, where the age and education range of the subjects were narrower compared with Lockie's sample population.

OVERALL PERCEPTION OF ORGANIC PRODUCE. Cronbach's alpha coefficients were computed for all constructs to gauge their internal consistency. All constructs exhibited Cronbach's alpha coefficients $>0.7$, thus justifying the aggregation of questions into constructs (Table 3). Two items were removed from the ethics construct and two from the policy/regulation construct to optimize the coefficients. Responses within each construct were averaged, resulting in a measure of agreement with the overall premise of each construct (Table 3 ). The mean response was significantly greater than 4.00 in four of the five constructs, indicating that most students had positive perceptions about organic produce. Organic produce is perceived as providing more health benefits and being more environmentally and ethically sound than conventional produce. The risk construct exhibited the highest mean among all constructs, indicating that most students perceived that consuming organic produce entailed less risk than consuming conventional produce. Finally, most students had a neutral perception of the existing policies and regulations affecting organic produce and organic agriculture. Results in all constructs agree with perceptions measured in other populations of college-aged consumers in the United States (Anderson et al., 2006), as well as rural and urban older populations in Thailand (Roitner-Schobesberger et al., 2008; Sangkumchaliang and Huang, 
2012) and Australia (Lea and Worsley, 2005).

Organic PRODUCE BUYERS VERSUS NONBUYERS. Most of the statements where differences in the frequency of agreement between organic buyers and nonbuyers occurred were in the risk construct (Table 4), suggesting that the main difference in perception between these groups is risk. More students expressed agreement with positively worded risk statements in the group of organic buyers than in the group of organic nonbuyers. Also, more students disagreed with all but one of the negatively worded statements in the group of organic buyers compared with the group of organic nonbuyers. This indicates that consumers in this sample population perceive organic produce as safer than conventional produce, a result similar to those of others (Lea and Worsley, 2005). Since low-risk perception appears to play a major role in the decision to purchase organic produce, the best way to influence the purchase decisions of subjects who do not buy organic produce in this sample population may be to target their perception of risk associated with organic produce. Low-risk perception toward organic produce is not necessarily a consequence of a high-risk perception toward conventional produce (Tung et al., 2012). Therefore, marketing and education efforts should focus on informing consumers about organic produce instead of comparing organic and conventional alternatives.

GENDER DIFFERENCES IN PERCEPTION. Most of the statements with significant differences between genders were found in the ethics construct (Table 5). However, there was no clear trend of gender effect on the perceived ethical soundness of organic production. Males expressed disagreement with both positively and negatively worded statements in greater proportion than females. That is, females were more agreeable on three out of the eight ethics statements compared with males. These differences in perception appear to be minor since both genders exhibited similar purchase behavior.

Table 3. General premises, internal consistency, and mean responses within health, environment, risk, ethics, and policy/ regulation constructs that motivate purchase of organic produce in a survey applied to a sample population of undergraduate students at the University of Florida.

\begin{tabular}{|c|c|c|c|c|c|}
\hline \multirow[b]{2}{*}{ Construct } & \multirow[b]{2}{*}{ Premise $^{\mathrm{z}}$} & \multicolumn{2}{|c|}{ Statements (no.) } & \multirow{2}{*}{$\begin{array}{l}\text { Cronbach's } \\
\text { alpha }^{\mathrm{x}}\end{array}$} & \multirow{2}{*}{$\begin{array}{l}\text { Mean } \\
\text { response }^{n}\end{array}$} \\
\hline & & Total & Used $^{\mathrm{y}}$ & & \\
\hline Health & $\begin{array}{l}\text { Consuming organic produce has more health benefits } \\
\text { than consuming conventional produce }\end{array}$ & 12 & 12 & 0.82 & $5.62 * * *$ \\
\hline Environment & $\begin{array}{l}\text { Organic produce is more environmentally sound than } \\
\text { conventional produce }\end{array}$ & 8 & 8 & 0.71 & $4.72 * * *$ \\
\hline Risk & $\begin{array}{l}\text { Consumption of organic produce entails less risk than } \\
\text { consumption of conventional produce }\end{array}$ & 9 & 9 & 0.81 & $5.64^{* * *}$ \\
\hline Policy/regulation & There is effective governmental regulation of organic produce & 7 & 5 & 0.80 & $3.94^{\mathrm{NS}}$ \\
\hline
\end{tabular}

${ }^{2}$ Statement that captures the underlying assertion in each construct.

y Number of statements used for mean response based on optimized Cronbach's alpha coefficient.

"Cronbach's alpha coefficient was used to gauge the internal consistency of each construct.

"Responses entered on a seven-point Likert scale (1 was "strongly disagree" and 7 was "strongly agree") were averaged across subjects within each construct. Positively and negatively worded statements were used. Negatively worded statements were reverse coded to make them align with each construct's premise

Ns, $* * *$ Nonsignificant or significant at $P \leq 0.001$

Table 4. Responses to statements in the risk construct where significant differences were found between subjects who buy organic produce and subjects who do not buy organic produce in a sample population of undergraduate students surveyed at the University of Florida.

\begin{tabular}{|c|c|c|c|c|c|c|c|c|}
\hline \multirow[b]{2}{*}{ Wording $^{\mathrm{z}}$} & \multirow[b]{2}{*}{ Risk statement } & $A^{y}$ & $\mathbf{N}^{\mathrm{x}}$ & $\mathrm{D}^{\mathrm{w}}$ & A & $\mathbf{N}$ & D & \multirow[b]{2}{*}{ Chi-square' } \\
\hline & & \multicolumn{3}{|c|}{ Buyer (\%) } & \multicolumn{3}{|c|}{ Nonbuyer (\%) } & \\
\hline $\mathrm{P}$ & $\begin{array}{l}\text { I would be willing to serve organic foods to my } \\
\text { friends }\end{array}$ & 94.3 & 3.9 & 1.7 & 81.1 & 8.1 & 10.8 & 0.003 \\
\hline $\mathrm{P}$ & Organic foods are completely safe to eat & 78.2 & 15.3 & 6.6 & 68.4 & 26.3 & 5.3 & 0.042 \\
\hline $\mathrm{N}$ & $\begin{array}{l}\text { Scientists cannot predict future outcomes of } \\
\text { organic technologies }\end{array}$ & 33.3 & 35.1 & 31.6 & 39.5 & 23.7 & 36.8 & 0.028 \\
\hline $\mathrm{P}$ & $\begin{array}{l}\text { Organic foods present no danger for future } \\
\text { generations }\end{array}$ & 49.8 & 32.2 & 18.1 & 28.9 & 44.7 & 26.3 & $<0.001$ \\
\hline $\mathrm{N}$ & Organic food will harm society more than help & 3.0 & 13.4 & 83.5 & 7.7 & 25.6 & 66.7 & 0.002 \\
\hline $\mathrm{N}$ & $\begin{array}{l}\text { It is dangerous to use organic techniques to } \\
\text { alter what we eat }\end{array}$ & 5.7 & 13.0 & 81.3 & 7.7 & 23.1 & 69.2 & 0.030 \\
\hline $\mathrm{N}$ & $\begin{array}{l}\text { The risks to people associated with organic } \\
\text { foods far outweigh the benefits }\end{array}$ & 4.3 & 18.2 & 77.5 & 10.3 & 33.3 & 56.4 & $<0.001$ \\
\hline
\end{tabular}

${ }^{\mathrm{z}}$ Statements were positively worded $(\mathrm{P})$ or negatively worded $(\mathrm{N})$ to account for any agreeability bias.

"Subjects found "in agreement" with the statement.

"Subjects found "neutral" with respect to the statement.

"Subjects found "in disagreement" with the statement.

${ }^{v}$ Chi-square tests were used to evaluate the differences between A:N:D ratios between the buyer and nonbuyer groups. 
Table 5. Responses to statements in the ethics construct where significant differences were found between gender in a sample population of undergraduate students surveyed at the University of Florida.

\begin{tabular}{|c|c|c|c|c|c|c|c|c|}
\hline \multirow[b]{2}{*}{ Wording $^{\mathrm{z}}$} & \multirow[b]{2}{*}{ Ethics statement } & $\mathbf{A}^{\mathbf{y}}$ & $\mathbf{N}^{\mathrm{x}}$ & $\mathrm{D}^{\mathrm{w}}$ & A & $\mathbf{N}$ & $\mathbf{D}$ & \multirow[b]{2}{*}{ Chi-square $^{v}$} \\
\hline & & \multicolumn{3}{|c|}{ Female (\%) } & \multicolumn{3}{|c|}{ Male (\%) } & \\
\hline $\mathrm{N}$ & $\begin{array}{l}\text { Changing the makeup of plants by using organic } \\
\text { means is not morally acceptable }\end{array}$ & 10.4 & 24.7 & 64.8 & 4.3 & 25.9 & 69.8 & 0.010 \\
\hline $\mathrm{P}$ & $\begin{array}{l}\text { Plants have the right to exist without manipulation } \\
\text { of their genes by humans }\end{array}$ & 33.7 & 32.1 & 34.2 & 19.0 & 33.6 & 47.4 & 0.001 \\
\hline $\mathrm{P}$ & Crops should only be enhanced by natural means & 32.1 & 30.4 & 37.5 & 30.4 & 18.3 & 51.3 & 0.003 \\
\hline
\end{tabular}

${ }^{2}$ Statements were positively worded $(\mathrm{P})$ or negatively worded $(\mathrm{N})$ to account for any agreeability bias.

"Subjects found "in agreement" with the statement.

"Subjects found "neutral" with respect to the statement.

"Subjects found "in disagreement" with the statement.

${ }^{v}$ Chi-square tests were used to evaluate the differences between A:N:D ratios between females and males.

EFFECT OF AGE ON PERCEPTION. The sample population was initially divided into three age groups. Since there were very few respondents older than 23 years old, two of the groups were combined, creating an "older than 20 years old" group for analysis. Responses in the majority of statements were not significantly different between age groups. Nine statements exhibited significantly different frequencies of agreement. Of these, four statements had very low (single digit) expected frequencies for one or more of the categories. Therefore, the chi-square tests may have underestimated the probability value of the comparison. These statements were not used to inform the conclusions of this study. Once these statements were removed, each construct had only one statement that exhibited significantly different frequencies of agreement, suggesting the perception of organic produce is consistent between the age groups in this sample population.

EFFECT OF EDUCATION ON PERCEPTION. Among the factors surveyed, formal education about organic production had the greatest impact on students' perceptions of organic produce, influencing perception in all but one of the constructs (Table 6). Four of the 12 statements in the health construct exhibited significantly different frequencies of agreement between the two survey groups. Fewer students disagreed with negatively worded health statements after the lecture than before. This suggests that after learning about organic crop production, students felt less certain about the desirable health effects attributed to organic produce.

Additionally, five out of the eight statements in the ethics construct exhibited significant differences in the frequency of agreement between groups. More students expressed agreement with negatively worded ethics statements after the lecture than before. Concomitantly, more students expressed disagreement with the positively worded statements in this construct after the lecture than before. Thus, formal education about organic crop production affected personal values and ethics, which are important factors in the perception of organic produce (Lea and Worsley, 2005). In this study, more information about organic crop production methods contributed to a bleaker perception of its ethical soundness, suggesting that positive ethical assessment of organic produce could be based on incomplete, inaccurate, or anecdotal evidence.

There were significant differences in the frequency of agreement in three out of eight statements in the environment construct between groups. More students expressed disagreement with two negatively and one positively worded statement in this construct after the lecture than before. There was no clear trend of the effect of formal education on the perceived environmental qualities of organic production. For example, more students agreed that organic crops use lesser amounts of pesticides before the lecture than after. Conversely, fewer students agreed that more chemicals are required to raise organic crops after the lecture than before. While contradictory, these results reveal a key aspect about the perception of pesticide/ chemical use in organic crop production, and agriculture as a whole. It appears that there is limited understanding of what these terms mean in the surveyed sample population. This stresses the necessity and the importance of agricultural education in college curricula.

Formal education also had an effect on the policy/regulation construct. All of the statements in this construct exhibited significant differences in the frequency of agreement between groups. Since this construct dealt with fact-based policy rather than values or perceptions, formal education had a much greater influence on student responses. More students expressed agreement with positively worded statements after the lecture than before the lecture. Concurrently, more students expressed disagreement with negatively worded statements after the lecture than before the lecture. Generally, after the lecture, students felt that there is adequate and effective regulation of organic food production and that this regulation is not unnecessarily burdensome on the private sector or public finances. Only after the lecture did the produced results align with those of other groups (Roitner-Schobesberger et al., 2008), suggesting that this sample population may indeed be particularly uninformed about policies and regulations in the organic foods market.

Statements in the risk construct were not significantly different between groups (data not shown), suggesting that formal education, as defined in this study, may not be enough to affect the risk assessment of students. This limited ability to influence people's risk assessment has been extensively studied by others (Frewer et al., 2003; Grunert, 2005).

Overall, formal education affected students' perception of organic produce but this change was not reflected in the likelihood of being organic consumers. Formal education 
Table 6. Responses to statements in health, ethics, environment, and policy/regulation constructs where significant differences were found in a sample population of University of Florida undergraduate students surveyed before or after a lecture on organic agriculture.

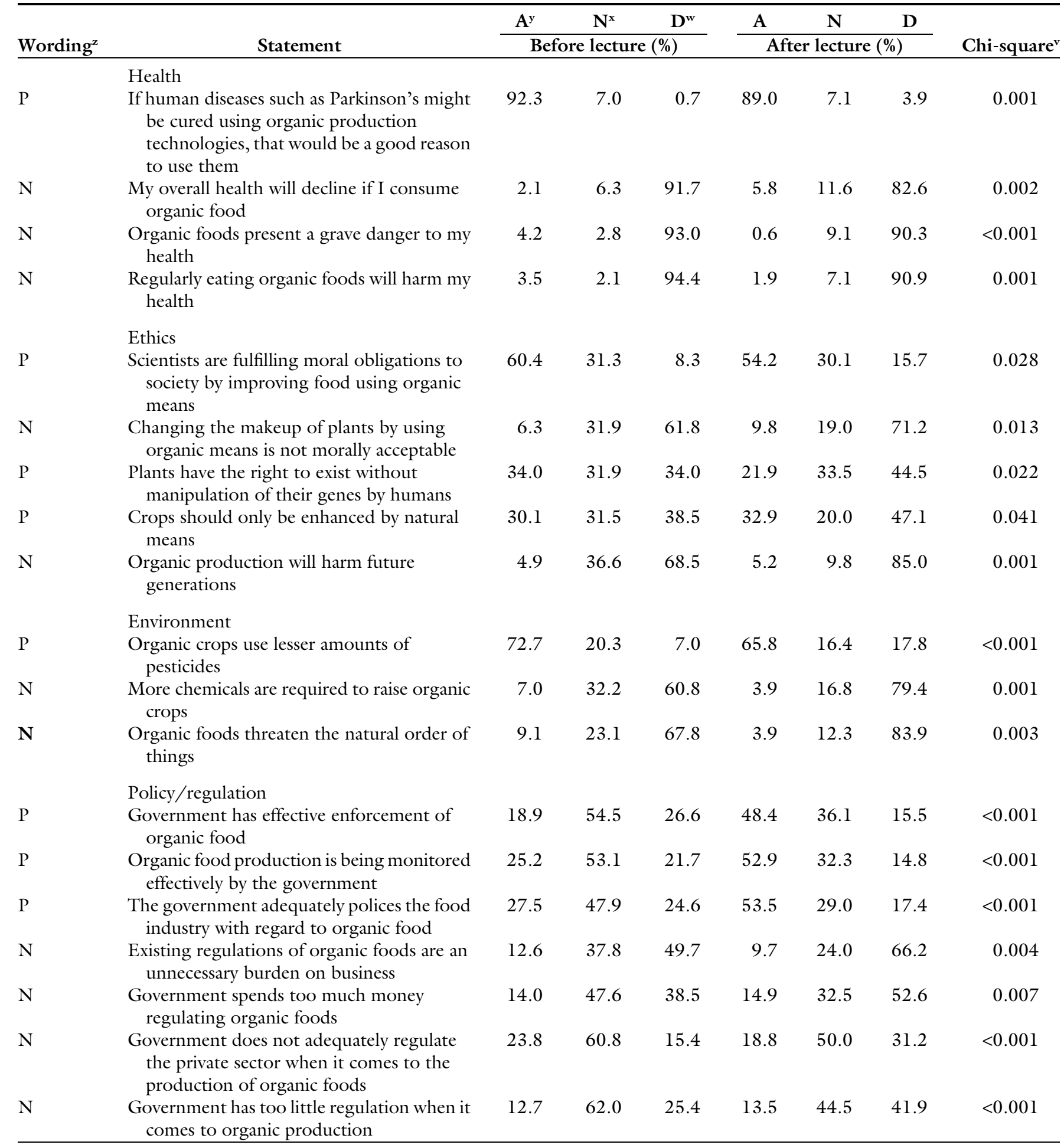

${ }^{\mathrm{z}}$ Statements were positively worded $(\mathrm{P})$ or negatively worded $(\mathrm{N})$ to account for any agreeability bias.

"Subjects found "in agreement" with the statement.

"Subjects found "neutral" with respect to the statement.

"Subjects found "in disagreement" with the statement.

${ }^{v}$ Chi-square tests were used to evaluate the differences between A:N:D ratios between the before lecture and after lecture groups.

influenced students' perception of organic produce as it pertained to health, environment, ethics, and policy/ regulation. On the other hand, education did not seem to have an effect on students' risk perception. In this sample population, the likelihood of being an organic consumer appears to be closely related to this construct. Lockie et al. (2002) and others have described the organic purchase phenomenon in terms of a balancing act 
where perceptions-but also need, convenience and opportunity - dictate the outcome. Given that the likelihood of being an organic consumer was measured using a binary question (buyer vs. nonbuyer), it is likely that even if formal education had an effect on this behavior, the chosen design would not have been able to capture it. Hence, the similar likelihood of being organic consumers in the pre-lecture and post-lecture groups was not unexpected. Additionally, no claim is made as to the effect of education on students' long-term consumption patterns. However, long-term studies with younger populations have shown that food sustainability education can have desirable effects, such as improved diets and increased community engagement (Jones et al., 2012). Thus, formal education about organic agriculture may be an important first step toward the more ambitious goal of agricultural literacy that many educators and institutions, both in the United States and elsewhere, have undertaken.

\section{Literature cited}

Anderson, J., C. Wachenheim, and W. Lesch. 2005. Perceptions of genetically modified and organic foods and processes: North Dakota college students. Agribusiness Appl. Econ. Rpt. No. 571, Dept. Agribusiness Applied Econ., North Dakota State Univ., Fargo.

Anderson, J., C. Wachenheim, and W. Lesch. 2006. Perceptions of genetically modified and organic foods and processes. AgBio Forum 9:180-194.

Bourn, D. and J. Prescott. 2002. A comparison of the nutritional value, sensory qualities and food safety of organically and conventionally produced foods. Crit. Rev. Food Sci. Nutr. 42:1-34.

Bravo, C.P., A. Cordts, B. Schulze, and A. Spiller. 2013. Assessing determinants of organic food consumption using data from the German National Nutrition Survey II. Food Qual. Prefer. 28:60-70.
Byrne, P., U. Toensmeyer, C. German, and H. Muller. 1991. Analysis of consumer attitudes toward organic produce and purchase likelihood. J. Food Distrib. Res. 22:49-62.

Chen, M. 2005. Organic fruits and vegetables: Potential health benefits and risks. Nutr. Noteworthy 7:1-5.

Dimitri, C. and C. Greene. 2002. Recent growth patterns in the U.S. organic foods market. U.S. Dept. Agr., Econ. Res. Serv., Agr. Info. Bul. No. AIB-777.

Frewer, L., J. Scholderer, and N. Lambert. 2003. Consumer acceptance of functional foods: Issues for the future. Brit. Food J. 104:714-731.

Gracia, A. and T. Magistris. 2008. The demand of organic foods in south of Italy: A discrete choice model. Food Policy 33:386-396.

Grunert, K. 2005. Food quality and safety: Consumer perception and demand. Eur. Rev. Agr. Econ. 32:369-391.

Hjelmar, U. 2011. Consumers' purchase of organic food products. A matter of convenience and reflexive practices. Appetite 56:336-344.

Huber, M., E. Rembiałkowska, D. Srednickab, S. Bügel, and L.P.L. van de Vijver. 2011. Organic food and impact on human health: Assessing the status quo and prospects of research. NJAS Wageningen. J. Life Sci. 58:103-109.

Jones, M., N. Dailami, E. Weitkamp, D. Salmon, R. Kimberlee, A. Morley, and J. Orme. 2012. Food sustainability education as a route to healthier eating: Evaluation of a multi-component school programme in English primary schools. Health Educ. Res. 27:448-458.

Lea, E. and A. Worsley. 2005. Australians' organic food beliefs, demographics and values. Brit. Food J. 107:855-869.

Lockie, S., K. Lyons, G. Lawrence, and K. Mummery. 2002. Eating green: Motivations behind organic food consumption in Australia. Sociol. Ruralis 42:23-40.

Naspetti, S. and R. Zanoli. 2009. Organic food quality and safety perception throughout Europe. J. Food Prod. Mktg. 15:249-266.

Ozguven, N. 2012. Organics foods motivations for consumers. Procedia Social Behav. Sci. 62:661-665.

Roitner-Schobesberger, B., I. Darnhofer, S. Somsook, and C. Vogl. 2008. Consumer perceptions of organic foods in Bangkok, Thailand. Food Policy 33:112121 .

Sangkumchaliang, P. and W. Huang. 2012. Consumers' perceptions and attitudes of organic food products in northern Thailand. Intl. Food Agribusiness Mgt. Rev. 15:87-102.

Seyfang, G. 2006. Ecological citizenship and sustainable consumption: Examining local organic food networks. J. Rural Stud. 22:383-395.

Shafie, F.A. and D. Rennie. 2012. Consumer perceptions towards organic food. Procedia Social Behavioral Sci. 49:360367.

Shi-ming, M. and J. Sauerborn. 2006. Review of history and recent development of organic farming worldwide. Agr. Sci. China 5:169-178.

Siderer, Y., A. Marquet, and E. Anklam. 2005. Need for research to support consumer confidence in the growing organic food market. Trends Food Sci. Technol. 16:332-343.

Storstad, O. and H. Bjørkhaug. 2003. Foundations of production and consumption of organic food in Norway: Common attitudes among farmers and consumers? Agr. Human Values 20:151-163.

Tung, S., C. Shih, S. Wei, and Y. Chen. 2012. Attitudinal inconsistency toward organic food in relation to purchasing intention and behavior. Brit. Food J. 114:997-1015.

U.S. Department of Agriculture. 2012. Organic market overview. 20 Aug. 2013. <http://www.ers.usda.gov/topics/ natural-resources-environment/organicagriculture/organic-market-overview.aspx\#. UhPd7mRKIWs $>$. 